University of Nebraska - Lincoln

DigitalCommons@University of Nebraska - Lincoln

Nutrition and Health Sciences -- Faculty

Publications

Nutrition and Health Sciences, Department of

$12-2006$

\title{
Clinical Registered Dietitians, Employers, and Educators Are Interested in Advanced Practice Education and Professional Doctorate Degrees in Clinical Nutrition
}

\author{
Annalynn Skipper \\ Annalynn Skipper and Associates, Oak Park, IL, Annalynn_Skipper@comcast.net \\ Nancy M. Lewis \\ University of Nebraska--Lincoln, nlewis2@unl.edu
}

Follow this and additional works at: https://digitalcommons.unl.edu/nutritionfacpub

Part of the Dietetics and Clinical Nutrition Commons

Skipper, Annalynn and Lewis, Nancy M., "Clinical Registered Dietitians, Employers, and Educators Are Interested in Advanced Practice Education and Professional Doctorate Degrees in Clinical Nutrition" (2006). Nutrition and Health Sciences -- Faculty Publications. 14.

https://digitalcommons.unl.edu/nutritionfacpub/14

This Article is brought to you for free and open access by the Nutrition and Health Sciences, Department of at DigitalCommons@University of Nebraska - Lincoln. It has been accepted for inclusion in Nutrition and Health Sciences - Faculty Publications by an authorized administrator of DigitalCommons@University of Nebraska - Lincoln. 


\title{
Clinical Registered Dietitians, Employers, and Educators Are Interested in Advanced Practice Education and Professional Doctorate Degrees in Clinical Nutrition
}

\author{
Annalynn Skipper PhD, RD, FADA, Annalynn Skipper and Associates, Oak Park, IL \\ Nancy M. Lewis PhD, RD, FADA, Professor, Department of Nutrition and Health Sciences, University of \\ Nebraska-Lincoln \\ Corresponding author - Annalynn Skipper, Annalynn Skipper and Associates, \\ PO Box 45, Oak Park, IL 60303; email Annalynn_Skipper@comcast.net
}

\begin{abstract}
A subset of registered dietitians (RDs) is known to practice at an advanced level, but a clear educational pathway supporting advanced medical nutrition therapy practice has not been identified. Thus, an electronic survey was designed to investigate interest of clinical RDs, employers, and educators in advanced practice competencies and professional doctorate degree programs in clinical nutrition. Usable responses were obtained from 440 of 978 (45\%) RDs, 61 of 107 (57\%) employers, and 76 of $114(67 \%)$ educators. Mean interest (5 = very interested, 1 = very uninterested) in obtaining advanced practice education was highest among RDs (3.93 \pm 1.01$)$ and was significantly different $(P<0.01)$ from employers $(3.74 \pm 1.28)$ and educators $(2.76 \pm 1.33)$. Interest in completing a professional doctorate in clinical nutrition was significantly $(P<0.01)$ different among RDs (3.05 \pm 1.28$)$, employers (3.18 \pm 1.30$)$, and educators $(2.3 \pm 1.34)$. Employers' mean interest score for hiring RDs with a professional doctorate in clinical nutrition was 4.02 \pm 0.93 . A subset of clinical RDs appears to be interested in obtaining advanced practice competency and enrolling in professional doctorate degrees in clinical nutrition. Clinical nutrition managers in academic medical centers may be interested in hiring advanced practice clinical RDs with professional doctorate degrees. Opportunities exist for educators to develop advanced practice educational experiences and professional doctorate degree programs.
\end{abstract}

$$
\text { * * * * }
$$

A subset of registered dietitians (RDs) practices medical nutrition therapy at an advanced level (1). These advanced practice food and nutrition professionals have a master's degree; at least 8 years' experience; multiple professional roles with complex and diverse responsibilities and functions; a diverse network of broad, geographically dispersed professional contacts; and an innovative, creative, and intuitive approach to practice that is reflective of a global perspective (1). Formal education and experience beyond what is required to enter the profession are considered pre- requisites to advanced practice (2). However, there is no clear educational pathway for RDs to achieve advanced practice status.

The majority of health professionals responsible for diagnosing and treating patients obtain a professional doctorate degree (3). A professional doctorate degree provides a level of professional skill beyond that required for a bachelor's degree, usually requires 4 years of college-level education before admission, is 3 to 4 years long, and blends didactic instruction with supervised practice (4). Professional doctorate degrees are used in medicine, dentistry, and pharmacy (3). Recently, physical therapy and audiology have adopted the professional doctorate degree to accommodate increased knowledge and support a more autonomous role. Advanced practice nurses will transition to the practice doctorate by 2015 (5).

At least one professional doctorate degree in clinical nutrition has been developed, but it is unknown if others exist (6). One survey of clinical dietitians' interest in professional doctorate degrees was conducted, but sufficient educator or student interest to justify program development has not been documented (7). It is unknown if jobs exist for RDs completing a professional doctorate degree. Thus we surveyed clinical RDs, employers, and educators to investigate interest in advanced practice competencies and professional doctorate degree programs in clinical nutrition.

\section{Materials and Methods}

Surveys

We developed an advanced medical nutrition therapy practice model (8). Competencies derived from the model were compared with the existing entry-level competencies to avoid overlap, and used as the basis for a survey (9). 
Three versions were developed, one for each of the groups surveyed. Section one contained seven background questions. Three sections contained questions about competencies and educational programs. Responses were recorded using a five-point Likert scale. Section five contained questions concerning barriers and benefits associated with practice doctorate degree programs.

For each version, sections two, three, and four were identical except that clinical RDs were asked about their interest in obtaining competencies, employers were asked about their interest in hiring clinical RDs with those competencies, and educators were asked about their interest in teaching the competencies. Section one contained different demographic questions and section five contained different barriers and advantages for each group. The terms "advanced practice RD," "advanced-level competencies," and "professional doctorate degree" were defined in the questionnaire to promote clarity.

A modified Delphi technique was used for content validity of the survey instruments. A panel of six experts, two in survey research, two educators with advanced practice credentials, and two employers with advanced practice credentials reviewed the surveys. A revised questionnaire was returned to the panel. No further changes were recommended. Electronic versions of the survey were created using Dragon Software (version 6.5v5, 2002, Waves in Motion, Phoenix, AZ). Results of an electronic pilot survey yielded a reliability coefficient of 0.84 .

\section{Sample}

Three groups were surveyed. Every 10th name was selected from the list of clinical RDs registered in each year from 1997 to 2000 to yield 250 names from each year for a total of 1,000 RDs. The sample was selected to reach RDs with $>3$ years (entry level), but $<8$ years (advanced practice) experience (1). Duplicate names were eliminated from the purchased list leaving 978 RDs. Employers were the clinical nutrition managers of the primary teaching affiliate hospitals $(n=120)$ for US medical schools listed in the directory of the Association of American Medical Colleges (10). Names and e-mail addresses were obtained for 107 employers. Graduate nutrition programs were identified from American Society of Nutritional Sciences and American Dietetic Association directories $(11,12)$. Duplicate programs were eliminated and electronic addresses obtained for 114 of 125 program directors.

\section{Survey Procedures}

The survey was conducted according to the four contact method of Dillman (13). The first three contacts were with e-mail messages containing a cover letter explaining the purpose of the survey and a link to the survey Web site. The fourth contact to nonresponders contained a cover letter, a questionnaire, and a stamped, preaddressed envelope. A small number of individuals with nonfunctional e-mail addresses were contacted using regular mail. The survey was conducted between November 2004 and February 2005. Institutional Review Board approval was obtained. Identifying information was removed upon receipt of responses; responses were stored in a locked office.

\section{Data Analysis}

Electronic survey data output was in an Excel (version 2003, Microsoft Corp, Redmond, WA) format file. Data from paper surveys were hand-entered into the Excel file, printed, and checked against original paper surveys for accuracy. The Statistical Package for the Social Sciences (version 12.0 for Windows, 2004, SPSS Inc, Chicago, IL) was used for data analysis. Descriptive statistics were calculated for demographic variables, barriers, and advantages. Mean response scores from electronic and paper samples were compared using $t$ tests. Differences in interest scores were analyzed using one-way analysis of variance and Scheffe's post hoc test. Differences between responders and nonresponders were tested using $\chi^{2}$ analysis of demographic variables. An a of $P \leq 0.05$ was preselected and the Bonferroni correction applied (14).

\section{Results}

Usable responses were obtained from 440 of 978 RDs (45\%), 61 of 107 employers (57\%), and 76 of 114 educators $(67 \%)$. No differences (adjusted a $0.05 / 28=0.0017$ ) were identified between paper and electronic responses that were then combined. The result of $\chi^{2}$ analysis revealed no differences between respondents and the sample for geographic location across all groups and year of registration for RDs, hospital bed size for employers, and type of educational institution for educators.

Almost $90 \%$ of clinical RDs $(n=391)$ stated advanced practice RDs were needed. Approximately 76\% (n = 334) considered themselves advanced practitioners, but only $38 \%(n=166)$ had earned a graduate degree, and none met experience criteria (15). Approximately $40 \%(n=175)$ responded that entry-level preparation was sufficient for advanced practitioners. Seventy percent of the 166 master's degree-prepared RDs $(n=117)$ received the degree before registration. Almost 30\% $(n=126)$ of the clinical RDs had considered obtaining a doctorate degree but were not interested in teaching or research.

Forty-nine percent of employers recognized the need for advanced practice RDs. Employers reported that $47 \%$ of RDs (397 of 853) reporting to them and at least 112 RDs in other departments functioned at an advanced level. Entry-level education was considered sufficient for advanced practice by $64 \%(n=39)$ of employers surveyed.

Educators reported 33 of $76(43 \%)$ departments offered a doctorate degree but only four $(5 \%)$ offered a clinical doctorate with another under development. One clinical program is housed in an academic medical center, one in a private university, and three in public universities. Faculty in $14(18 \%)$ departments had discussed offering a professional doctorate program. Approximately 50\% (n = 34) of respondents reported pressure to increase graduate enrollments. About half of departments actively recruited RDs into their doctorate degree program. Approximately one fourth of 429 doctorate degree students were RDs.

Mean interest scores for advanced practice competencies are shown in Table 1. Interest in obtaining advanced practice competence was independent of years of experience. Competencies where interest scores were significantly higher for clinical RDs than educators may represent 
Table 1. Scores of registered dietitians (RDs), employers, and educators surveyed for interest in advanced medical nutrition therapy competencies (5 = very interested, 1 = very uninterested $)$

\begin{tabular}{|c|c|c|c|c|}
\hline & $\begin{array}{l}\text { RDs } \\
(n=440)^{a}\end{array}$ & $\begin{array}{l}\text { Employers } \\
(\mathrm{n}=61)^{\mathrm{b}}\end{array}$ & $\begin{array}{l}\text { Educators } \\
(\mathrm{n}=76)^{\mathrm{c}}\end{array}$ & $\begin{array}{l}P \\
\text { value }^{\mathrm{d}}\end{array}$ \\
\hline & \multicolumn{3}{|c|}{$\leftarrow$ mean \pm standard deviation $\rightarrow$} & \\
\hline Providing efficient and effective consultation and referral & $4.16 \pm 0.89$ & $4.46 \pm 0.81$ & $3.42 \pm 1.32$ & $<0.01^{\text {ef }}$ \\
\hline Implementing and modifying nutrition-related drug therapy & $4.39 \pm 0.88$ & $4.28 \pm 0.93$ & $3.38 \pm 1.23$ & $<0.01^{\text {ef }}$ \\
\hline Ordering and modifying macro- and micronutrient doses & $4.23 \pm 0.93$ & $4.55 \pm 0.68$ & $3.66 \pm 1.15$ & $<0.01^{\text {ef }}$ \\
\hline Identifying, measuring, and modifying patient achievement of nutrition outcomes & $4.12 \pm 0.87$ & $4.52 \pm 0.70$ & $3.63 \pm 1.39$ & $<0.01^{\text {efg }}$ \\
\hline Using diagnostic and clinical reasoning to diagnose nutrition disorders & $4.47 \pm 0.80$ & $4.69 \pm 0.62$ & $3.83 \pm 1.25$ & $<0.01^{\text {ef }}$ \\
\hline Designing, implementing, and modifying evidence-based nutrition intervention & $3.94 \pm 1.00$ & $4.28 \pm 0.84$ & $4.36 \pm 0.92$ & $<0.01^{\text {eg }}$ \\
\hline Providing leadership on nutrition issues within and outside the profession & $3.88 \pm 0.98$ & $4.3 \pm 0.92$ & $3.8 \pm 1.26$ & $0.01^{\mathrm{fg}}$ \\
\hline
\end{tabular}

a. Usable responses were obtained from 440 of 978 RDs (45\%).

b. Usable responses were obtained from 61 of 107 employers (57\%).

c. Usable responses were obtained from 76 of 114 educators $(67 \%)$.

d. Differences between groups, based on analysis of variance.

e. Significant difference between RDs and educators $(P<0.05)$ using Scheffe's post hoc test.

f. Significant difference between employers and educators $(P<0.05)$ using Scheffe's post hoc test.

g. Significant difference between RDs and employers $(P<0.05)$ using Scheffe's post hoc test.

Table 2. Scores of registered dietitians (RDs), employers, and educators responding to a survey of interest in professional doctorate degrees $(5=$ very interested and $1=$ very uninterested)

\begin{tabular}{|c|c|c|c|c|}
\hline & $\begin{array}{l}\text { RDs } \\
(n=440)^{a}\end{array}$ & $\begin{array}{l}\text { Employers } \\
(\mathrm{n}=61)^{\mathrm{b}}\end{array}$ & $\begin{array}{l}\text { Educators } \\
(\mathrm{n}=76)^{\mathrm{c}}\end{array}$ & $\begin{array}{l}P \\
\text { value }^{\mathrm{d}}\end{array}$ \\
\hline & \multicolumn{3}{|c|}{$\leftarrow$ mean \pm standard deviation $\rightarrow$} & \\
\hline Interest in completing a professional doctorate degree & $3.06 \pm 1.27$ & $3.18 \pm 1.30$ & $2.30 \pm 1.34$ & $<0.01^{\mathrm{ef}}$ \\
\hline Employing someone with a professional doctorate degree & $3.30 \pm 1.11$ & $4.02 \pm 0.93$ & $3.08 \pm 1.35$ & $<0.01^{\mathrm{fg}}$ \\
\hline Interest in developing courses for a professional doctorate program & $2.78 \pm 1.25$ & $3.15 \pm 1.06$ & $2.75 \pm 1.34$ & 0.09 \\
\hline Interest in developing a professional doctorate program & $2.68 \pm 1.29$ & $2.77 \pm 1.18$ & $2.43 \pm 1.25$ & 0.22 \\
\hline
\end{tabular}

a. Usable responses were obtained from 440 of $978 \mathrm{RDs}(45 \%)$.

b. Usable responses were obtained from 61 of 107 employers $(57 \%)$.

c. Usable responses were obtained from 76 of 114 educators $(67 \%)$.

d. Differences between groups, based on analysis of variance.

e. Significant difference between RDs and educators $(P<0.05)$ using Scheffe's post hoc test.

f. Significant difference between employers and educators $(P<0.05)$ using Scheffe's post hoc test.

g. Significant difference between RDs and employers $(P<0.05)$ using Scheffe's post hoc test.

program development opportunities. Interest in professional doctorate degrees in clinical nutrition is shown in Table 2. Mean educator scores for teaching in a professional doctorate program were low, but 15 of 76 program directors were interested or very interested in establishing a professional doctorate. Interest in developing a professional doctorate program was independent of university Carnegie classification or land grant status. Because employers had the highest interest scores in developing advanced practice and professional doctorate degrees it is possible that academic medical centers would be interested in housing these programs.

\section{Challenges and Advantages}

Clinical RDs anticipated both challenges and advantages to a professional doctorate degree. The primary challenges were sufficient time $(\mathrm{n}=371 ; 84 \%)$ and money for tuition (n $=341 ; 78 \%$ ). Fewer RDs saw insufficient advanced practice job opportunities $(n=238 ; 54 \%$ ), employer support for flex- 
ible scheduling to attend classes $(\mathrm{n}=228 ; 52 \%)$, and tuition reimbursement $(\mathrm{n}=179 ; 41 \%)$ as challenges.

Clinical RDs anticipated increased salary $(\mathrm{n}=310 ; 70 \%)$, sense of accomplishment $(n=310 ; 70 \%)$, respect from other health care professionals $(\mathrm{n}=300 ; 68 \%)$, ability to help patients $(n=283 ; 64 \%)$, career satisfaction $(n=253 ; 58 \%)$, job opportunities $(\mathrm{n}=248 ; 56 \%)$, skills $(\mathrm{n}=225 ; 51 \%)$, and a broader career perspective $(n=219 ; 50 \%)$ as advantages of the professional doctorate degree. To a lesser degree, RDs anticipated increased respect from other food and nutrition professionals $(\mathrm{n}=197 ; 45 \%)$ and increased job responsibility $(\mathrm{n}=148 ; 34 \%)$.

For employers, a potential challenge to hiring advanced practice RDs was sufficient salary $(n=56 ; 92 \%)$. Fewer were concerned about utilizing advanced practice expertise $(\mathrm{n}=32 ; 53 \%)$ and role competition from other food and nutrition professionals $(26 ; 43 \%)$ or health professionals (n $=17 ; 28 \%$ ). Potential advantages included improved quality of care $(n=53 ; 87 \%)$, better documentation of patient care outcomes $(\mathrm{n}=45 ; 74 \%)$, and decreased training time $(\mathrm{n}=37 ; 61 \%)$. Employers also mentioned improved identification of nutrition problems and the ability to address them using research $(n=33 ; 55 \%)$, increased respect from other professionals $(n=32 ; 53 \%)$, and greater contributions to the patient nutrition outcomes literature $(n=31 ; 51 \%)$. In other words, employers were interested in hiring RDs with a professional doctorate degree, but concerned about salaries. The educational level for health professions is escalating as needed knowledge and skills increase (3). Employers may want to hire RDs with professional doctorate degrees to maintain a staff with similar credentials to other health care workers, but this is speculation.

Educators identified funding for additional faculty (n $=63 ; 83 \%)$, sufficient faculty $(\mathrm{n}=57 ; 75 \%)$, administrative support $(\mathrm{n}=53 ; 70 \%)$, and faculty with practitioner experience $(n=49 ; 65 \%)$ as potential challenges. Other perceived challenges included research opportunities $(n=49 ; 65 \%)$, funding for facilities $(\mathrm{n}=47 ; 62 \%)$, broadening the departmental mission $(n=44 ; 58 \%)$, faculty interest $(n=41 ; 54 \%)$, and sufficient students $(n=25 ; 33 \%)$. Possible benefits include increased enrollment $(n=36 ; 47 \%)$ and dietetics research opportunities $(\mathrm{n}=36 ; 47 \%)$. Achieving a broader mission $(\mathrm{n}=34 ; 45 \%)$ and increased faculty with practitioner experience $(n=33 ; 43 \%)$ were also perceived benefits. Few programs included clinical experience $(n=9 ; 12 \%)$. Joint research appointments in clinical facilities were more common $(\mathrm{n}=29 ; 38 \%)$ than joint clinical appointments $(\mathrm{n}=$ $7 ; 10 \%)$.

The methodology for this study included an Internet survey. Such surveys have become a popular research tool due to reduced data entry, response time, and possibly costs (16). Lower response rates to Internet surveys have been reported, but not consistently demonstrated (17 and 18). Electronic surveys of food and nutrition professionals are unavailable for comparison, but the $45 \%$ response rate is similar to paper surveys of clinical RDs and employers (19 and 20). A recent electronic survey of undergraduate dietetics program directors yielded a $46 \%$ response rate, which cannot be directly compared with the $67 \%$ response rate from graduate program directors in this survey (21). Topic salience may influence response rates, but we cannot speculate if it influenced these results (17 and 18).

Nonresponse bias is another limitation of survey meth- odology, but was not detected based on available demographic factors. It is unknown if other factors could have distinguished nonrespondents. It is unknown if unemployed RDs did not respond to the survey because the cover letter solicited responses from practicing RDs. It is also unknown if data entry errors were made by the respondents.

The employers in this research were clinical nutrition managers in academic medical centers; therefore, results cannot be generalized to clinical nutrition managers in all hospitals. It is possible that other potential employers for advanced practice RDs exist. A survey of community hospitals, diabetes and dialysis centers, and outpatient nutrition clinics is needed to confirm our findings. Results of this survey include interest levels for clinical RDs, employers, and educators in advanced medical nutrition therapy competencies and professional doctorate degrees in clinical nutrition.

\section{Conclusions}

- A subset of clinical RDs is interested in obtaining advanced practice competency and enrolling in a professional doctorate degree program in clinical nutrition.

- There may be employment opportunities available for advanced practice clinical RDs in academic medical centers and the clinical nutrition managers in these institutions may be interested in hiring clinical RDs with advanced practice competency who are graduates of professional doctorate programs.

- Opportunity exists for educators who wish to develop advanced practice educational experiences and professional doctorate degree programs.

Acknowledgments - This manuscript is a contribution of the University of Nebraska Agricultural Research Division, Research Bulletin No. 14683. This research was supported in part through the Hatch Act.

\section{References}

1. R. T. Bradley, W. Y. Young, P. Ebbs, and J. Martin, Characteristics of advanced-level dietetics practice: A model and empirical results, J Am Diet Assoc 93 (1993), pp. 196-202.

2. American Dietetic Association, Scope of Dietetics Practice Framework Documents (2005); online at http://www.adajournal.org/article/PIIS000282230500307X/fulltext

3. A. Skipper and N. M. Lewis, A look at the educational preparation of the health diagnosing and treating professions: Do dietitians measure up?, J Am Diet Assoc 105 (2005), pp. 420-427.

4. US Department of Education, Institute of Educational Studies, Digest of Educational Statistics (2004); online at http:// www.nces.edu.gov/pubs

5. American Association of Colleges of Nursing, AACN Position statement on the practice doctorate in nursing (2005); online at http://www.aacn.nche.edu/DNP/DNPPositionStatement.htm 
6. R. Touger-Decker, Advanced-level practice degree options: Practice doctorates in dietetics, J Am Diet Assoc 104 (2004), pp. 1456-1458.

7. B. W. Christie and M. A. Kight, Educational empowerment of the clinical dietitian: A proposed practice doctorate curriculum, J Am Diet Assoc 93 (1993), pp. 173-176.

8. A. Skipper and N. M. Lewis, Using initiative to achieve autonomy: A model for advanced practice in medical nutrition therapy, J Am Diet Assoc 106 (2006), pp. 1219-1225.

9. K. S. Bruening, B. E. Mitchell, and M. M. Pfeiffer, 2002 accreditation standards for dietetics education, J Am Diet Assoc 102 (2002), pp. 566-577.

10. Directory of American Medical Education, American Association of Medical Colleges, Washington, DC (2003).

11. American Society for Nutritional Sciences, Graduate nutrition programs (2004); online at http://www.asns.org

12. American Dietetic Association, Advanced degree programs (2004); online at http://www.eatright.org

13. D. A. Dillman, Mail and Internet Surveys, John Wiley and Sons, New York, NY (2000).

14. In: F. J. Gravetter and L. B. Wallnau, Editors, Statistics for the Behavioral Sciences, Wadsworth, Belmont, CA (2000).

15. R. T. Bradley, Fellow of the American Dietetic Association credentialing program: Development and implementation of a portfolio-based assessment, J Am Diet Assoc 96 (1996), pp. 513-517.

16. P. Leece, M. Bhandari, S. Sprague, M. F. Swiontkowski, E. H. Schemitsch, P. Tornetta, P. J. Devereaux, and G. H. Guyatt, Internet vs mailed questionnaires: A controlled comparison, J Med Internet Res 6 (2004), pp. e39-e46.

17. P. Edwards, I. Roberts, M. Clarke, C. DiGuiseppi, S. Pratap, R. Wentz, and I. Kwan, Increasing response rates to postal questionnaires: Systematic review, BMJ 324 (2005), pp. 1183-1191.

18. K. Sheehan, E-mail survey response rates: A review, J Comp Mediated Comm 6 (2001), pp. 1-20.

19. A. B. Barr, M. A. Walters, and D. W. Hagan, The value of experiential education in dietetics, J Am Diet Assoc 102 (2002), pp. 1458-1460.

20. J. F. Simmons, A. Skipper, L. J. Lafferty, and M. B. Gregoire, A survey of perceived benefit and differences in therapy provided by credentialed and non-credentialed nutrition support dietitians, J Parenter Enteral Nutr 27 (2003), pp. 282-286.

21. J. E. Short and M. M. Chittooran, Nutrition education: A survey of practices and perceptions in undergraduate dietetics education, J Am Diet Assoc 104 (2004), pp. 1601-1604. 